\title{
AVALIAÇÃO DOS ACIDENTES ESCORPIÔNICOS NO ESTADO DE SÃO PAULO
}

\section{ARTIGO ORIGINAL}

VOLITZKI, Elton ${ }^{1}$, GAGGINI, Marcio Cesar Reino ${ }^{2}$

VOLITZKI, Elton. GAGGINI, Marcio Cesar Reino. Avaliação dos acidentes escorpiônicos no estado de São Paulo. Revista Científica Multidisciplinar Núcleo do Conhecimento. Ano 06, Ed. 06, Vol. 04, pp. 29-43. Junho de 2021. ISSN: 2448-0959, Link de acesso: https://www.nucleodoconhecimento.com.br/saude/acidentesescorpionicos, DOI: 10.32749/nucleodoconhecimento.com.br/saude/acidentesescorpionicos

\section{RESUMO}

No Brasil existem cerca de 160 espécies de escorpiões, sendo as pertencentes ao gênero Tityus, as principais responsáveis por graves incidentes. No Estado de São Paulo, o escorpionismo é o maior problema de saúde pública relacionado a acidentes por animais peçonhentos. Em 2020, foram registrados 36.109 acidentes no estado, o maior número de escorpionismo em mais de 30 anos. A presente revisão teve como objetivo apresentar as características epidemiológicas e o atendimento as vítimas de acidentes escorpiônicos do Estado de São Paulo. O trabalho foi realizado através de bibliografia cientifica encontrada no PubMed, no Google Acadêmico e Scientific and Electronic Library Online (Scielo), além de dados divulgados pelo Centro de Vigilância Epidemiológica e da Secretaria de saúde do Estado de São Paulo. Foi observado que o escorpionismo vem crescendo anualmente e a redução do número de ocorrências

\footnotetext{
${ }^{1}$ Graduação em Medicina.

${ }^{2}$ Orientador. Mestrado em Engenharia Biomédica.
}

RC: 87873

Disponível em: https://www.nucleodoconhecimento.com.br/saude/acidentes-escorpionicos 
deve ser feita de forma preventiva, devendo incluir ações governamentais e a participação ativa de população. É essencial garantir o acesso as informações e estrutura adequada para os profissionais de saúde, agilizando-se ao máximo o atendimento as vítimas de escorpionismo.

Palavras-Chave: Escorpionismo, Escorpiões No Estado De São Paulo, Tityus.

\section{INTRODUÇÃO}

Os escorpiões são os artrópodes[3] mais antigos conhecidos pelo homem, apresentando registros científicos da existência dos escorpiões há mais de 450 milhões de anos. Atualmente, aproximadamente 1.600 espécies de escorpiões, distribuídas em 18 famílias, são descritas no mundo. Destas espécies, apenas cerca de 30, pertencentes à família Buthidae, são perigosas e são responsáveis por envenenamentos graves ou morte (NENCIONI et al., 2018).

O envenenamento por picada de escorpião ou quadro clínico decorrente do acidente escorpiônico é denominado escorpionismo, sendo relativamente comum nos trópicos e subtrópicos dos cinco continentes (CIRUFFO et al., 2012). Apresentando-se como um problema de saúde pública e uma ameaça real em vários países do mundo, em particular na América do Sul e Central, Norte da África, Oriente Médio e Índia (BAHLOUL et al., 2017; CHIPPAUX E GOYFFON, 2008)

No Brasil, ocorrem cerca de 160 espécies de escorpiões, sendo as pertencentes ao gênero Tityus as principais responsáveis por graves incidentes. Destacando-se quatro espécies: T. serrulatus, T. bahiensis, T. stigmurus e T. obscurus (NENCIONI et al., 2018).

A peçonha do escorpião é produzida por um par de glândulas no último segmento da cauda (metassoma) e chamado de telson. No final de sua cauda existe uma estrutura afiada com dois orifícios por onde as toxinas são inoculadas. O escorpião golpeia suas presas, como insetos e pequenos vertebrados, para que ocorra a captura. Por

RC: 87873

Disponível em: https://www.nucleodoconhecimento.com.br/saude/acidentes-escorpionicos 
ser um animal que só se alimenta de presas vivas, o veneno imobiliza a presa para que suas pinças o auxiliem na alimentação (PUCCA et al., 2015).

Figura 1. Morfologia do escorpião

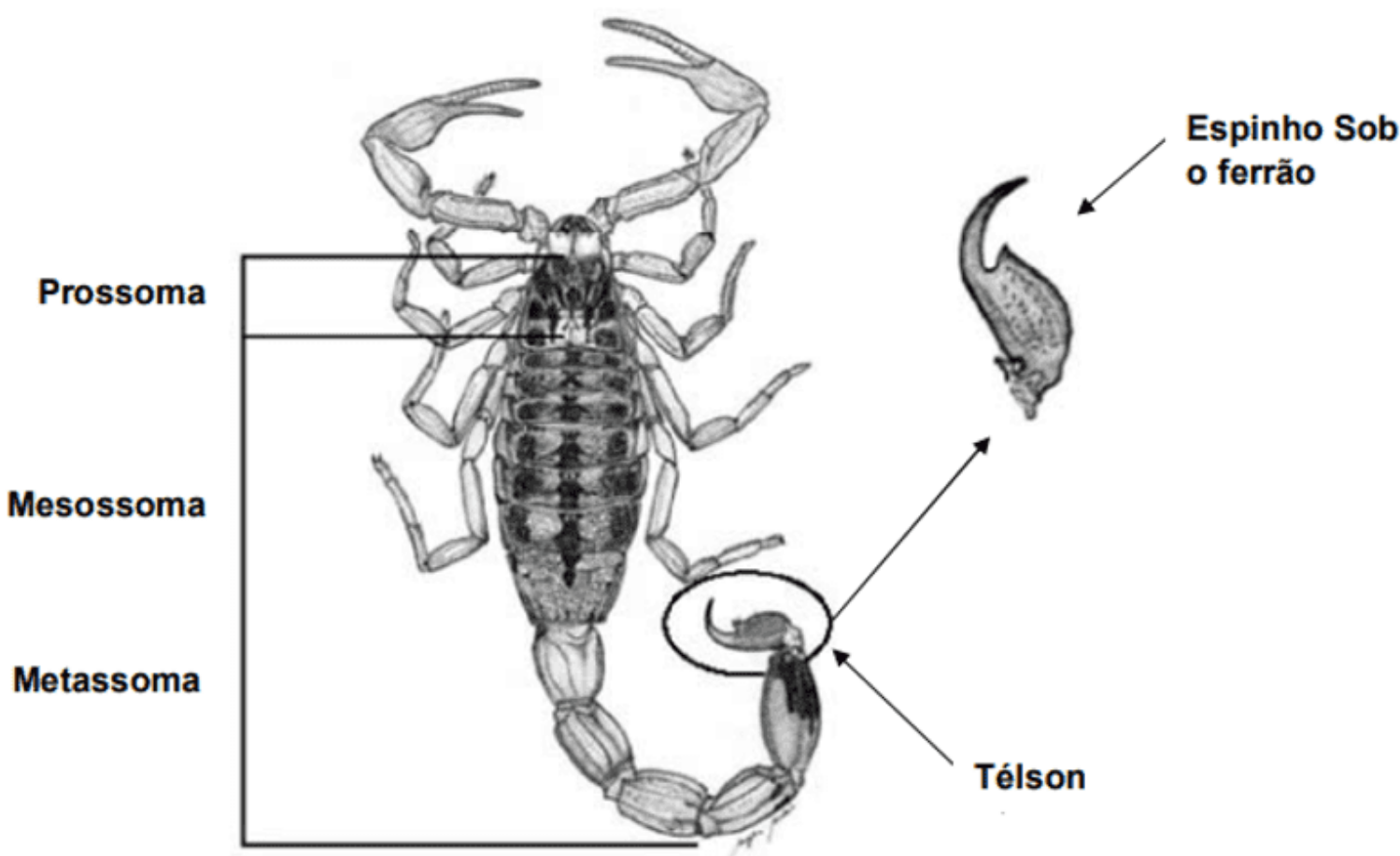

Fonte: BRASIL, 2009.

O veneno inoculado é formado por uma mistura heterogênea de toxinas com variantes entre as espécies. Por exemplo, o veneno de $T$. serrulatus é composto por diversos compostos como muco, sais inorgânicos, lipídios, aminas, nucleotídeos, enzimas, inibidor de calicreína, peptídeo natriurético, proteínas de alta massa molecular, peptídeos, aminoácidos livres e neurotoxinas (PUCCA et al., 2015). Diversas espécies do gênero Tityus apresentam neurotoxinas com ação rápida e que promovem uma extensa liberação de neurotransmissores como epinefrina, norepinefrina e acetilcolina (RIBEIRO et al., 2001).

O escorpionismo é um problema de saúde pública negligenciado no Brasil, que vem ganhando importância devido ao crescente número de envenenamentos e mortes,

RC: 87873

Disponível em: https://www.nucleodoconhecimento.com.br/saude/acidentes-escorpionicos 
principalmente nos centros urbanos. De acordo com o sistema público de saúde do país, em 2007, foram registradas 61 mortes, enquanto, em 2017, teriam sido 90 óbitos por picadas de escorpião. Entre 2013 a 2017, cerca de 83\% das mortes ocorreram em até 48 horas após a picada (BRASIL, 2018; TORREZ et al., 2019).

A acelerada urbanização observada no Brasil nas últimas décadas, sem a adequada criação de infraestrutura básica (como água, luz, tratamento de esgoto e coleta regular de lixo), tem proporcionado condições para a proliferação de escorpiões oportunistas e invasores, tais como o T. serrulatus e T. stigmurus (TORREZ et al., 2019).

São Paulo é o Estado mais populoso do Brasil, sendo estimado mais de 46 milhões de habitantes e com 645 municípios (IBGE, 2020). O estado apresenta grandes dimensões territoriais, com características que podem favorecer os acidentes com escorpiões, como: a presença de muitas áreas turísticas em contextos ecológicos, rodovias de difícil acesso, usinas produtoras de açúcar e álcool e com grande número de trabalhadores rurais (ESTADO DE SÃO PAULO, 2019).

Em 2020, foram registrados 36.109 acidentes, o maior número de escorpionismo em mais de 30 anos. Segundo o Centro de Vigilância Epidemiológica (ESTADO DE SÃO PAULO, 2019), o escorpionismo apresenta-se como "o maior problema de saúde pública relacionado a acidentes por animais peçonhentos."

O presente trabalho tem como objetivo desenvolver uma revisão das informações sobre as características epidemiológicas e clínicas dos acidentes escorpiônicos do Estado de São Paulo. Deste modo, identificando a problemática observada no Estado, o atendimento as vítimas de envenenamento por picada de escorpião e suas formas de combate.

Foi realizada, para este trabalho, uma revisão sistemática e qualitativa de artigos, livros e trabalhos acadêmicos encontrados na base de dados MedLine, através do PubMed, no Google Acadêmico e Scientific and Electronic Library Online (Scielo). Usando como descritores da pesquisa diferentes termos em português e inglês, sendo

RC: 87873

Disponível em: https://www.nucleodoconhecimento.com.br/saude/acidentes-escorpionicos 
os principais: "acidentes com escorpiões", "escorpionismo", "Scorpion venom", "Scorpionism in Brazil" e "accidents and deaths from scorpion". Todos os trabalhos citados foram diretamente consultados para verificação das informações publicadas e as pesquisas foram feitas em maio de 2021. Além disso, foram utilizados dados divulgados pelo Centro de Vigilância Epidemiológica e da Secretaria de saúde do Estado de São Paulo.

\section{ESCORPIÕES NO ESTADO DE SÃO PAULO}

Os escorpiões são carnívoros, alimentando-se principalmente de insetos e outros invertebrados. Os predadores naturais compreendem algumas aves, répteis (como lagartos e lagartixas), anfíbios e algumas espécies de aranhas. Os escorpiões são mais ativos durante meses quentes, com hábitos noturnos e costumam se esconder durante o dia. Esses animais são encontrados nas cidades, ocorrendo em áreas verdes, terrenos abandonados, linhas de trem, em galerias de esgoto, de águas pluviais e de instalações elétricas e áreas em construção ou com entulho de obras (LOURENÇO, 2018).

Em São Paulo, o escorpionismo tem apresentado considerável aumento, particularmente, nas áreas urbanas. Na década 1990, os casos de acidentes por escorpiões se concentravam no noroeste do Estado, entretanto, as ocorrências deixaram de ser concentrar nesta região e afetar grande parte da região paulista (CAMPOLINA, 2006).

No estado de São Paulo, especialmente, três espécies são consideradas de importância em saúde pública: Tityus bahiensis (escorpião marrom), Tityus serrulatus (escorpião amarelo) e Tityus stigmurus (escorpião amarelo do Nordeste), todos com, em média, $7 \mathrm{~cm}$ de comprimento.

As espécies Tityus serrulatus e Tityus stigmurus são mais relatadas no ambiente urbano paulista, geralmente, em galerias de esgoto, águas pluviais e bueiros. Devido à ausência de predadores naturais, presença de alimento abundante e água RC: 87873

Disponível em: https://www.nucleodoconhecimento.com.br/saude/acidentes-escorpionicos 
disponível (Secretaria Municipal da Saúde da Prefeitura da Cidade de São Paulo, 2021). Além disso, essas espécies são partenogenéticas, reproduzindo-se mais rapidamente que as espécies sexuadas, podendo cada fêmea ter duas crias com aproximadamente, em média, 20 filhotes cada, por ano (PUCCA et al., 2015). Enquanto, a espécie Tityus bahiensis ocorre em regiões mais verdes e reprodução sexuada, suas populações não aumentam tão rapidamente se comparadas as outras duas espécies (CIDADE DE SÃO PAULO, 2021).

Figura 2. Escorpiões. (A) Escorpião amarelo (Tityus serrulatus), (B) Escorpião do nordeste (Tityus stigmurus) e (C) Escorpião marrom (Tityus bahiensis).

A

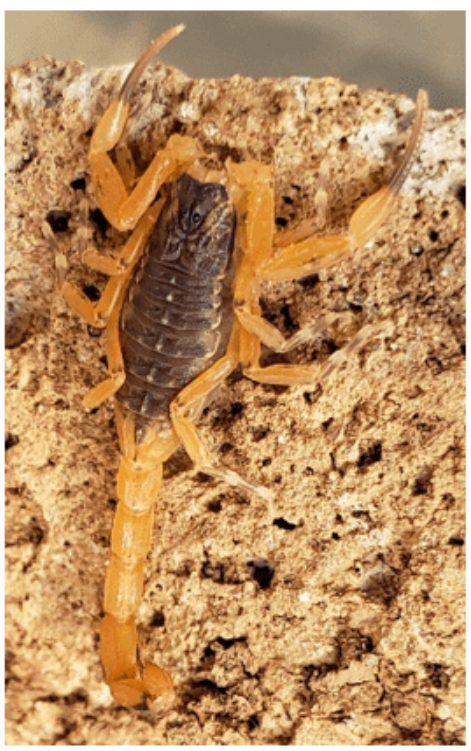

B

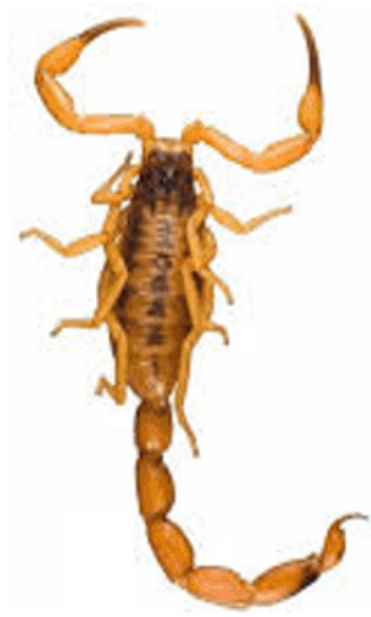

C

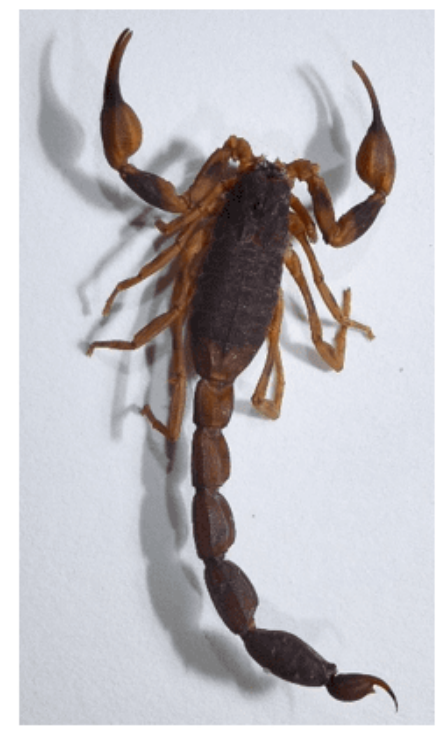

Fonte: Prefeitura Da Cidade De São Paulo, 2021.

O aumento das populações de escorpiões em áreas urbanas estaria associado ao crescimento desordenado dos centros urbanos, pois proporcionam condições cada vez mais favoráveis à proliferação desses animais. No ambiente urbano, esses escorpiões encontram abrigos como lixo, entulhos e materiais de construção, e uma alimentação farta, com baratas e outros insetos, principalmente nas áreas periurbanas com salubridade e saneamento mais escassos (CAMPOLINA, 2006). 
Outro problema é a falta de competidores e de predadores naturais, como macacos, quatis, sapos e anfíbios, também permite o aumento da população de escorpiões (SOARES et al. 2002).

A partir de 1988 os dados de acidentes escorpiônicos passaram a ser sistematicamente coletados pelo Programa Nacional de Controle de Acidentes por Animais Peçonhentos, do Ministério da Saúde. Entretanto, a incorporação do Sistema de Informação de Agravos de Notificação (SINAN), em 1997, permitiu uma análise mais consistente do escorpionismo no Brasil. Em São Paulo, os dados são apresentados na Figura 3, demonstrando um crescimento expressivo nas últimas décadas. Além disso, em 2020, houve o registro de 36.109 casos, o maior número desde o início dos registros (Figura 3.A, ESTADO DE SÃO PAULO, 2021).

$\mathrm{O}$ ano de 2020 também apresentou um total de 7 óbitos registados. Enquanto, o ano de 2018, apresentou 30.476 acidentes e 13 mortes, sendo o ano com maior número de fatalidades desde o início dos registros (Figura 3.B, dados Divisão de Zoonose, 2021).

RC: 87873

Disponível em: https://www.nucleodoconhecimento.com.br/saude/acidentes-escorpionicos 
Figura 3. Dados do Estado de São Paulo. (A) Número de acidentes ao longo dos anos e (B) número de óbitos.

A

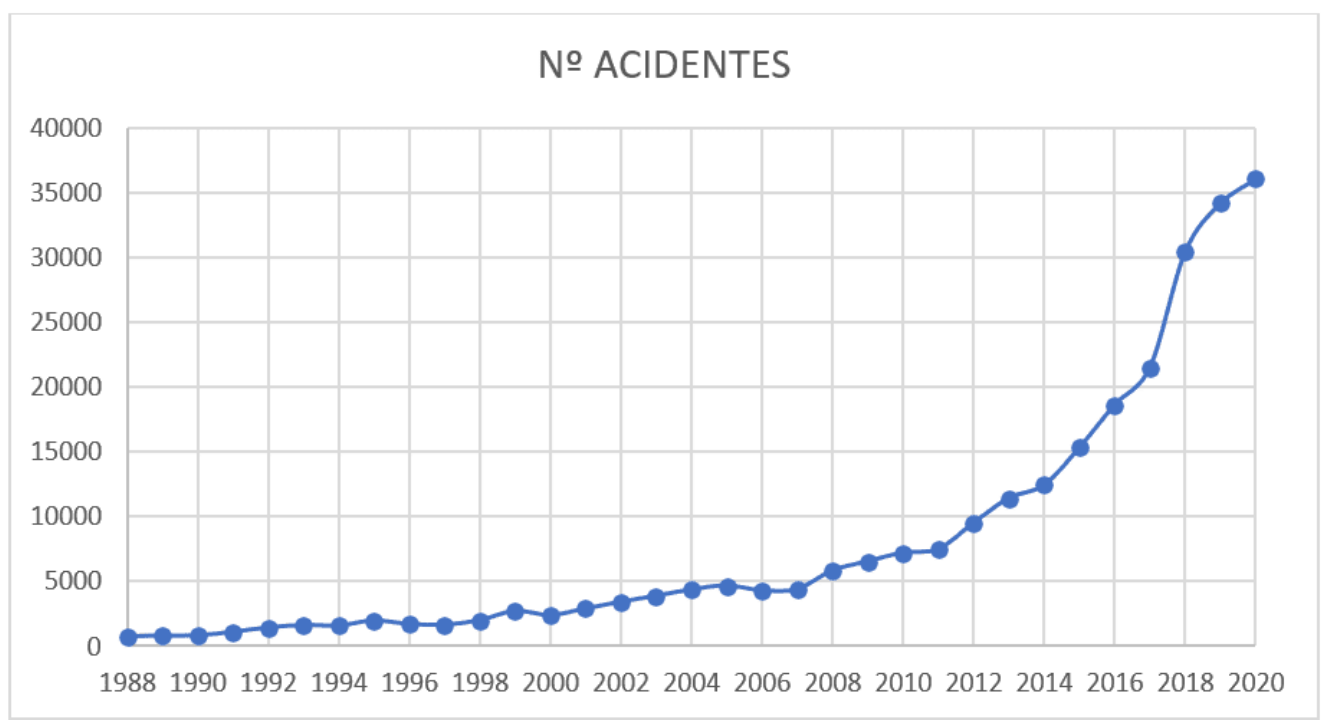

Fonte:

Dados fornecidos pelo Divisão de Zoonoses - CVE - Sinanw e Sinan Net (ESTADO DE SÃO PAULO, 2021). Gráfico feito pelo autor.

B

\section{ÓBITOS}

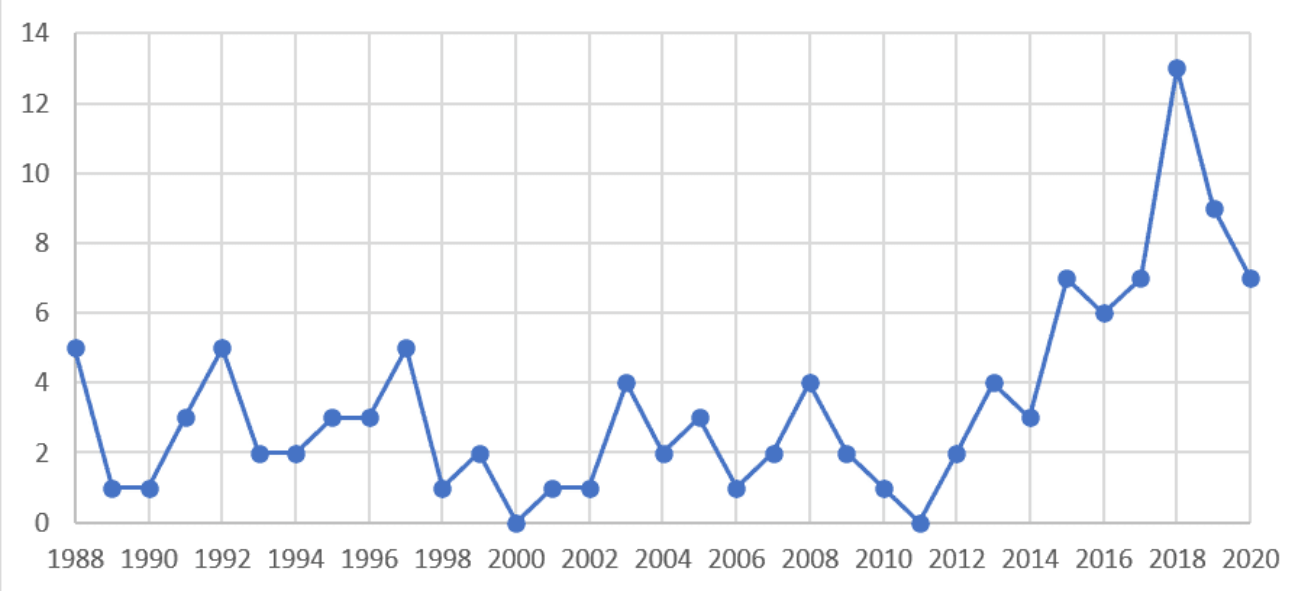

Fonte: Dados fornecidos pelo Divisão de Zoonoses - CVE - Sinanw e Sinan Net (ESTADO DE SÃO PAULO, 2021). Gráfico feito pelo autor.

RC: 87873

Disponível em: https://www.nucleodoconhecimento.com.br/saude/acidentes-escorpionicos 
Em acidentes escorpiônicos o tempo de atendimento às vítimas, inclusive para a soroterapia antiescorpiônica, e a adequada condução diagnóstico-terapêutica compreendem fatores fundamentais para a recuperação do paciente. Desta forma, em 1986, foi criado o Programa Nacional de Controle de Acidentes por Animais Peçonhentos (PNCAAP) normatizando o diagnóstico e tratamento de acidentes que incluíam escorpiões no Brasil. Além disso, medidas estaduais também foram desenvolvidas para acelerar a viabilização do tratamento, como o desenvolvimento do Centro de Vigilância Epidemiológica "Alexandre Vranjac" (CVE) que coordena e normatiza o Sistema de Vigilância Epidemiológica no Estado de São Paulo.

Desta forma, os dados do CVE apontam que o número de acidentes com escorpiões esteja crescendo anualmente. Entretanto, a taxa de letalidade[4], felizmente, não segue a mesma tendência (Figura 4, ESTADO DE SÃO PAULO, 2021). Enquanto o aumento dos casos ocorre associado a expansão da área urbana, redução das áreas verdes e alterações nas cadeias tróficas (CAMPOLINA, 2006), a letalidade não sofre graves alterações. A letalidade seria mantida, quase que constante, como resultado do avanço das estratégias para o atendimento as pessoas vítimas de acidentes por escorpião.

RC: 87873 
Figura 4. Letalidade de acidentes com escorpiões do Estado de São Paulo.

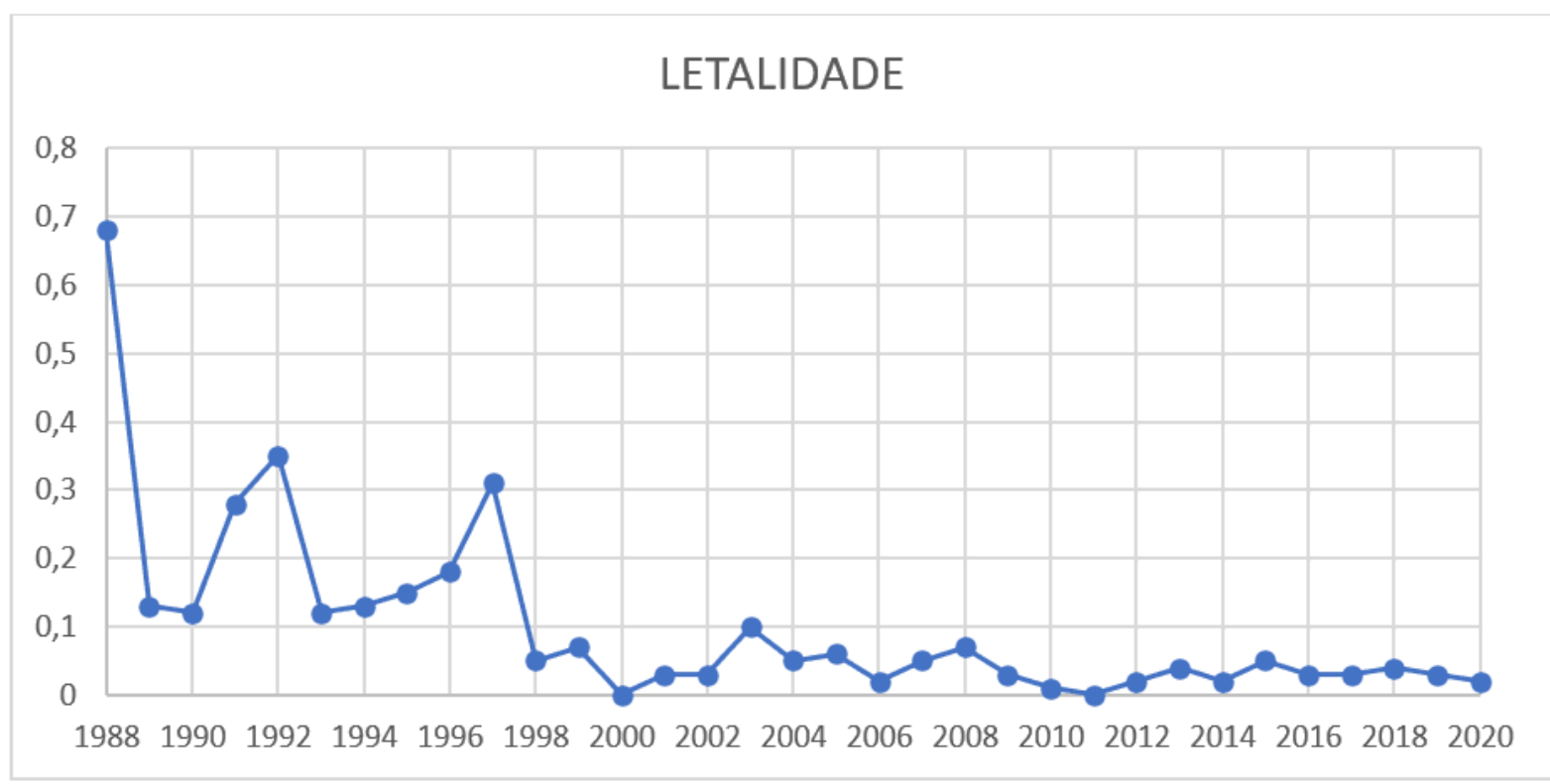

Fonte: Dados fornecidos pelo Divisão de Zoonoses - CVE - Sinanw e Sinan Net (ESTADO DE SÃO PAULO, 2021). Gráfico feito pelo autor.

\section{ATENDIMENTO AS PESSOAS VítIMAS DE ACIDENTES POR ESCORPIÃO}

Estima-se que mais de $60 \%$ dos acidentes ocorram com pessoas do sexo masculino em idade produtiva (20 a 59 anos), sendo o grupo com maior risco de exposição: os trabalhadores da construção civil, coletores de lixo, pecuaristas, feirantes, jardineiros, biólogos e veterinários, praticantes de ecoturismo e comunidades que sofreram enchentes ou que vivem próximos a lixões. Entretanto, os grupos de pessoas com maior risco de gravidade são as crianças até 10 anos e os idosos. No Estado de São Paulo, 86\% das vítimas fatais (25 dos 29 óbitos), entre 2018 e 2020, tinham menos de 10 anos (ESTADO DE SÃO PAULO, 2021; PREFEITURA DE SÃO PAULO, 2019).

Os principais efeitos causados pelos venenos de escorpião são dor e inflamação no local da picada, com vermelhidão, inchaço e calor local. Entretanto, em casos mais graves, podem ocorrer enjoos e vômitos, tontura, dor de cabeça, tremores e espasmos

RC: 87873

Disponível em: https://www.nucleodoconhecimento.com.br/saude/acidentes-escorpionicos 
musculares. O caso ainda pode evoluir para danos ao miocárdio, arritmias cardíacas e edema pulmonar, principalmente, devido à liberação de mediadores do sistema nervoso autônomo e, possivelmente, no sistema nervoso central e no sistema inflamatório (NEONCINI et al., 2018).

A rapidez do atendimento é essencial, especialmente, nos grupos de risco. Deste modo, buscando agilizar o atendimento das vítimas, foram criadas as Normas Técnicas Para o Atendimento às Vítimas de Escorpionismo no Estado de São Paulo pelo CVE. Essas normas determinam que o tempo máximo entre o acidente e a administração da soroterapia antiescorpiônica deve ser de 1h30min. Neste tempo, considera-se 40min para o deslocamento do acidentado até o primeiro atendimento e assistência inicial e mais $50 \mathrm{~min}$ para o deslocamento da vítima até o ponto estratégico de referência para diagnóstico e tratamento do escorpionismo/soroterapia (ESTADO DE SÃO PAULO, 2021).

Os pontos Estratégicos ou Unidades de Referência para diagnóstico e terapia do escorpionismo são compostas por equipes devidamente capacitadas, e portadoras de soros específicos, realizando o atendimento regional dos acidentes por animais peçonhentos, dentre eles, por escorpião. Atualmente, o Estado de São Paulo apresenta 212 pontos estratégicos para atendimento às vítimas de escorpionismo, em 200 municípios. Estabelecendo assim "distâncias de no máximo 50min entre cada município e sua unidade de referência para diagnóstico e tratamento do escorpionismo/soroterapia antiescorpiônica" (ESTADO DE SÃO PAULO, 2021).

O acidentado por escorpião pode dar entrada em qualquer serviço de Saúde. Enquanto as unidades de saúde precisam ter conhecimento da localização do ponto estratégico mais próximo. Devendo crianças até 10 anos ter prioridade no pronto atendimento e, no caso de crianças com sintomatologia sistêmica no primeiro atendimento, preferencialmente, encaminhar para o ponto estratégico de referência com UTI (ESTADO DE SÃO PAULO, 2021; CUPO e CUSTODIO, 2012). 
Os pontos de referência devem ser previamente avisados sobre a transferência da vítima, devendo se preparar para o atendimento de forma mais efetiva e podem, quando esta for a melhor opção, transferir o soro. Em casos especiais, quando identificado risco de remoção do paciente, poderá ser solicitado o transporte dos soros antivenenos até o local de atendimento inicial do paciente, se houver estrutura técnica e física para tal atendimento (ESTADO DE SÃO PAULO, 2021; CUPO e CUSTODIO, 2012).

No caso da possibilidade de uma picada de escorpião sem confirmação ou ausência de sinais e sintomas, o paciente deve permanecer em observação por pelo menos 4 horas. Entretanto, a pós a confirmação do acidente escorpiônico e admissão na clínica médica, deve-se diagnosticar a gravidade do caso e seguir o protocolo correspondente (ESTADO DE SÃO PAULO, 2021; CUPO e CUSTODIO, 2012).

Os quadros leves apresentam marcas do local da picada, com dor moderada a forte intensidade, frequentemente irradiada, podendo ser acompanhada de parestesia, eritema, edema discreto e sudorese. Podem ocorrer manifestações sistêmicas isoladas como discreta taquicardia e agitação devido a dor e ansiedade. Devem ser observados por 4 a 6 horas, podendo receber analgésicos e compressa morna e/ou bloqueio anestésico local. Se houver evolução do quadro clínico, deve-se adotar o protocolo para os quadros moderados e graves (ESTADO DE SÃO PAULO, 2021; CUPO e CUSTODIO, 2012).

Para os quadros moderados ocorrem sintomas semelhantes aos quadros leves, mas podem apresentar vômitos, sudorese discreta, taquicardia, taquipneia e hipertensão leves. Deve-se fazer a internação hospitalar para monitorização, uso de pelo menos 3 ampolas de soro antiescorpiônico e podem ser utilizadas medidas analgésicas como nos casos leves. Se houver agravamento do caso, adota-se o protocolo de casos graves. Em caso de crianças, o primeiro vômito já caracteriza a necessidade urgente do uso do soro antiescorpiônico (ESTADO DE SÃO PAULO, 2021; CUPO e CUSTODIO, 2012).

$\mathrm{RC}: 87873$

Disponível em: https://www.nucleodoconhecimento.com.br/saude/acidentes-escorpionicos 
Nos quadros graves existe a presença de manifestações intensas e evidentes, como: náuseas frequentes vômitos, sialorreia, sudorese profusa, hipotermia, palidez cutânea, tremores, agitação alternada com prostração e alterações cardíacas. Além disso, quadros de hipóxia acentuada como a presença de extremidades frias e pálidas que podem evoluir para choque e óbito. É aconselhável fazer a internação em CTI e uso de pelo menos 6 ampolas de soro antiescorpiônico (ESTADO DE SÃO PAULO, 2021; CUPO e CUSTODIO, 2012).

Os casos de acidentes com escorpião são de notificação compulsória (Portaria de Consolidação № 4, de 28 de setembro de 2017), devendo todo caso suspeito ser investigado de forma cuidadosa, especialmente em relação ao local provável de infecção. A notificação é obrigação do serviço de atendimento, sendo realizada por meio da Ficha de Investigação de Acidentes por Animais Peçonhentos do Sinan e enviada para a Unidade de Vigilância em Saúde (PREFEITURA DE SÃO PAULO, 2019).

\section{MEDIDAS DE PREVENÇÃO}

No ambiente natural os escorpiões desempenham importante função no equilíbrio ecológico como predadores de outros seres vivos e devem ser preservados. Entretanto, nas áreas urbanas, são necessárias ações evitar sua proliferação, através do correto manejo ambiental e planejamento urbano. Além disso, programas para busca e captura ativa desses animais podem ser necessários (ESTADO DE SÃO PAULO, 2021).

Devido ao aumento do escorpionismo no estado de São Paulo a Superintendência de Controle de Endemias (Sucen) vem aprimorando o Programa de Assessoria aos Municípios (PAM) Escorpião. Esse programa existe desde a década de 90 e busca "a cooperação técnica com os municípios e dar orientação para a organização do serviço, com oferecimento de capacitação e planejamento estratégico de atividades para o controle de animais nocivos" (SUCEN, 2018). A associação do PAM e dos 
Centros de Controle de Zoonoses locais foram responsáveis pela captura e registro de 55.561 escorpiões, de novembro de 2018 a janeiro de 2021. Onde, 53.935 eram Tityus serrulatus, 822 Tityus bahiensis, 7 Tityus stigmurus e restante não foi possível a identificação (MORAIS et al., 2021).

A ocorrência de acidentes com aracnídeos, como o escorpião, está conectada em fatores como a falta de saneamento básico e más condições de moradias. Os grandes centros urbanos apresentam abrigos, locais de difícil acesso para o homem e predadores naturais, impossibilitando assim um controle biológico. Até mesmo nas áreas verdes é comum encontrar lixos espalhados, tornando-se possíveis abrigos para esses animais. Além disso, o acúmulo de lixo nas cidades permite o desenvolvimento de baratas e outros insetos que são fontes de alimentação para os escorpiões (STROPA, 2010).

Santos (2020) aponta a população e o próprio poder público como responsáveis pela elevação do aumento de casos escorpionismo, devido ao descaso com o lixo e desestruturação ambiental. Deste modo, o problema com os escorpiões torna-se também uma questão socioambiental. Para Guedes e Guedes (2007) existe a necessidade de investimento na estruturação urbana e saneamento básico. Outro ponto é a disposição do lixo em locais não apropriados que podem favorecer o surgimento de epidemias. Além disso, é necessário investir na educação ambiental da população, tendo como objetivo a diminuição dos impactos ambientais e evitando o descontrole das populações de aracnídeos e insetos.

\section{CONCLUSÃO}

No Estado de São Paulo as principais medidas de controle e manejo de escorpiões baseiam-se na remoção/coleta de escorpiões e na modificação das condições ambientais para torná-los um ambiente desfavorável à proliferação desses aracnídeos. Entretanto, é necessário compreender melhor e agir contra os fatores já conhecidos, tais como o manejo ambiental e organização urbana, que estão 
influenciando o alargamento da distribuição geográfica e o estabelecimento de novas populações de escorpiões em áreas urbanas.

O estado já apresenta medidas que auxiliem o rápido atendimento às vítimas de escorpionismo, devendo ser cuidadosamente seguidas. Além disso, é importante garantir o preparo dos profissionais de saúde (empenhados na coleta dos animais ou no atendimento clínico) e dos pontos de atendimento aos pacientes, contribuindo para a redução do número de acidentes e agilidade do atendimento, consequentemente, diminuindo os níveis de mortalidade.

\section{REFERÊNCIAS}

BAHLOUL, M.; REGAIEG, K.; CHABCHOUB I.; KAMMOUN, M.; CHTARA, K.; BOUAZIZ M. Les envenimations scorpioniques graves: physiopathologie et rôle de l'inflammation dans la défaillance multiviscérale. Med Sante Trop, 27, 214-221, 2017.

BRASIL. Ministério da Saúde. Secretaria de Vigilância em Saúde (SVS) - Sistema de Informação de Agravos de Notificação (SINAN). Saúde de A a Z. Acidentes por animaispeconhentos. Brasília, 2018. Disponível em: http://portalms.saude.gov.br/saude-de-a-z/acidentes-por-animais-peconhentos. Acessado em 4 mai 2021.

BRASIL. Ministério da saúde. Secretaria de vigilância em saúde - Departamento de vigilância epidemiológica. Manual de controle de escorpiões. Brasília, 2012.

CAMPOLINA, D. Georreferenciamento e estudo clínico-epidemiológico dos acidentes escorpiônicos atendidos em Belo Horizonte, no serviço de toxicologia de Minas Gerais. 2006, 32-47 f. Dissertação (mestrado). Universidade Federal de Minas Gerais, Belo Horizonte, 2006.

CHIPPAUX JP, GOYFFON M. Epidemiology of scorpionism: a global appraisal. Acta Trop, v.107, p. 71-9, 2008. 
CIRUFFO, P. D.; COUTINHO, L. O.; BORONI, L. D.; DINIZ, A. E. T.; DINIZ, W. F. Escorpionismo: Quadro clínico e manejo dos pacientes graves. Revista Medicina Minas Gerais, 2012.

CUPO, P.; CUSTODIO, V.I.C. Protocolo Clínico e de Regulação para Abordagem dos Acidentes por Aracnídeos. In: SANTOS, J.S.; ALVES JR., G.P.; BLIACHERIENE, A.C.; FOSTER, A.C. (Org.). Protocolo Clínico e de Regulação: Acesso à Rede de Saúde. $1^{\underline{a}}$ ed. Rio de Janeiro: Elsevier, 2012, v.2, p. 469-490.

ESTADO DE SÃO PAULO. Programa De Assessoria Aos Municípios Para Vigilância E Controle De Escorpião No Estado De São Paulo (PAM ESCORPIÃO), 2019.

Disponível: <http://200.144.1.24/escorpio/ajuda/Diretriz\%20SUCEN/Diretriz\%20Escorpi\%C3\%A3 ०\%20outubro\%20.pdf>.Acesso 18 mai 2021.

GUEDES, I.C.; GUEDES, R.C.M. Resíduo de construção e demolição (RCD): reaproveitamento, reuso e reciclagem - uma análise sobre a gestão de resíduos na cidade de Guarulhos-SP. 2007. Trabalho de conclusão de curso de Especialização em Gestão Ambiental. Curso de Pós-graduação em Gestão Ambiental, Faculdade Padre João Bagozzi, Guarulhos, 2007.

INSTITUTO BRASILEIRO DE GEOGRAFIA E ESTATÍSTICA (IBGE). Estimativas do panorama nacional. Disponível em: https://cidades.ibge.gov.br/brasil/sp/panorama. Acessado em 5 mai 2021.

LOURENÇO, W. R. Scorpions and life-history strategies: from evolutionary dynamics toward the scorpionism problem. Journal of Venomous Animals and Toxins Including Tropical Diseases, 24(1), 2018.

MORAIS, G.S.C.; BARLETA, C.; GOMES, A.H.A.; SAMPAIO, S.M.P.; SILVA, R.A.; BERSUSA, A.P.S.; SILVA, S.C. Sistema Escorpião da Sucen - um retrato do 
encontro/captura do escorpião no estado de São Paulo. Informe epidemiológico. BEPA, 2021, v.18(205), p.23-35.

NENCIONI, A.; NETO, E. B.; DE FREITAS, L. A.; DORCE, V. Effects of Brazilian scorpion venoms on the central nervous system. The journal of venomous animals and toxins including tropical diseases, v.24, 2018.

PREFEITURA DA CIDADE DE SÃO PAULO. Secretaria Municipal da Saúde. Escorpiões, $2021 . \quad$ Disponível em: $<$ https://www.prefeitura.sp.gov.br/cidade/secretarias/saude/vigilancia_em_saude/con trole_de_zoonoses/animais_sinantropicos>. Acesso em: 07 mai 2021.

PREFEITURA DA SÃO PAULO. Acidentes por escorpião, 2019. Disponível: $<$ https://www.prefeitura.sp.gov.br/cidade/secretarias/upload/saude/protocolo_manejo _cl\%C3\%ADnico_escorpiao.pdf> Acesso em 17 mai 2021.

PUCCA, M.B.; CERNI, F.A.; PINHEIRO JUNIOR, E.L.; BORDON, K.C.F.; AMORIM, F.G.; CORDEIRO, F.A.; LONGHIM, H.T.; CREMONEZ, C.M.; OLIVEIRA, G.H.; ARANTES, E.C. Tityus serrulatus venom - A lethal cocktail. Toxicon, v.108, p.272284, 2015.

RIBEIRO, L. A.; RODRIGUES, L.; JORGE, M. T. Aspectos clínicos e epidemiológicos do envenenamento por escorpiões em São Paulo e municípios próximos. Revista de Patologia Tropical. v. 30. n. 1. p. 83-92. 2001.

SANTOS, A.M.L. Influência dos fatores socioambientais na ocorrência de acidentes escorpiônicos em um município do nordeste brasileiro, Alagoas, Brasil. Dissertação apresentada ao Programa de Pós-graduação Análise de Sistemas Ambientais do Centro Universitário CESMAC, Alagoas, 2020.

SOARES, M.R.M.; AZEVEDO, C.S.; DE MARIA, M. Escorpionismo em Belo Horizonte, MG: um estudo retrospectivo. Rev. Soc. Bras. Med. Trop., v. 35, n. 4, p. 359-363, 2002.

$\mathrm{RC}: 87873$

Disponível em: https://www.nucleodoconhecimento.com.br/saude/acidentes-escorpionicos 
STROPA, A. A. Effect of architectural angularity on refugia selection by the brown spider, Loxosceles gaucho. Medical and Veterinary Entomology, v. 24, n. 3, p. 273$277,2010$.

TORREZ, P.P.Q. et al. Scorpionism in Brazil: exponential growth of accidents and deaths from scorpion stings. Rev. Soc. Bras. Med. Trop., v. 52, 2019.

\section{APÊNDICE - REFERÊNCIA DE NOTA DE RODAPÉ}

3. filo de animais invertebrados, que se caracteriza pela presença de corpo segmentado, membros locomotores articulados em número par e exoesqueleto quitinoso

4. Calculada dividindo-se o número de óbitos pelo número de acidentes vezes 100 Enviado: Maio, 2021.

Aprovado: Junho, 2021.

$\mathrm{RC}: 87873$ 